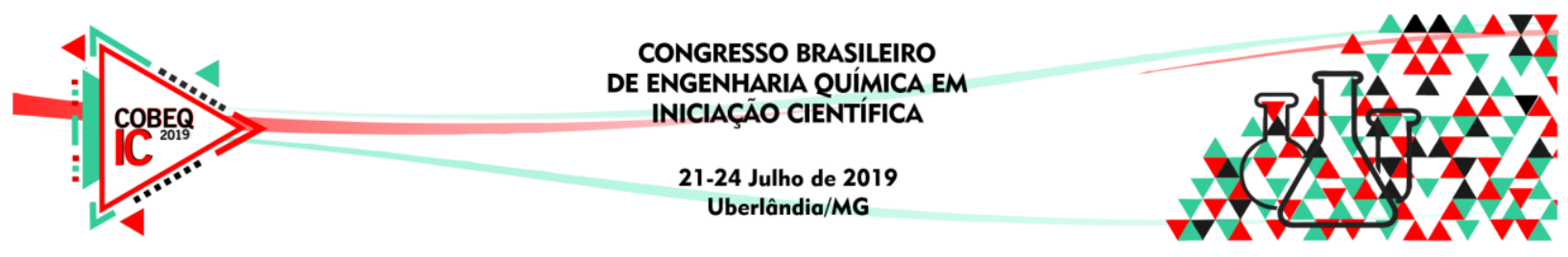

\title{
REMOÇÃO DE CÁDMIO E CROMO USANDO CASCA DE CAFÉ COMO ADSORVENTE EM PROCESSO BATELADA
}

\author{
A. S. XAVIER ${ }^{1}$, L. H. M. SILVA ${ }^{2}$, M. N. MORAIS ${ }^{2}$, T. S. T. GARCIA ${ }^{2}$, D. O. SILVA ${ }^{2}$ \\ ${ }^{1}$ Universiade Federal de Uberlândia, Faculdade de Engenharia Química \\ ${ }^{2}$ Centro Universitário de Patos de Minas, Faculdade de Engenharia Química \\ E-mail para contato: danielos@unipam.edu.br
}

\begin{abstract}
RESUMO - Um dos principais problemas no descarte de efluente é a presença de metais pesados, pois reduzem a capacidade autodepurativa das águas devido à ação tóxica sobre os microrganismos. A casca do café possui propriedades adsortivas, com capacidade de se encharcar de liquido, permitindo que o fluido introduza em seu interior. O Brasil é o maior produtor mundial de café, responsável por $31,9 \%$ com 49,64 milhões de sacas. Neste sentido, o presente trabalho buscou-se aliar a alta capacidade de adsorção da casca de café ao tratamento de um efluente sintético. Para a realização das análises, foi preparado um efluente sintético com Cádmio e Cromo, tratou-se a casca de café, utilizando três concentrações $(\mathrm{g} / \mathrm{L})$ de adsorvente e em dois difrentes tempos de adsorção. Com a adsorção foi alcançado um remoção de até $24,19 \%$ de Cádmio e 38,95\% de Cromo com a menor massa testada nos experimentos.
\end{abstract}

\section{INTRODUÇÃO}

Segundo a ONUBR, a disponibilidade de recursos hídricos está intrinsecamente ligada à qualidade da água, causado principalmente pelo despejo inadequado, por falta de tratamento, entre outros. Dentro desse contexto, o descarte inadequado de metais pesados tem gerado uma grande preocupação, pois sua presença nos efluentes reduzem a capacidade auto-depurativa das águas devido à ação tóxica que eles exercem sobre os microorganismos (AMORIM, 2000).

Para minimizar o efeito destas substâncias sobre o meio ambiente, muitas pesquisas têm sido desenvolvidas em busca de novas tecnologias para removê-las de resíduos sólidos e líquidos, como a investigação de novos adsorventes naturais, pois as técnicas atuais já estão ficando obsoletas e caras para o tratamento de resíduos e efluentes (WALESKA et al., 2008).

A casca do café possui propriedades adsortivas, com capacidade de se encharcar de liquido, permitindo que o fluido introduza em seu interior. Segundo CIOLA (1981), esse processo ocorre devido à posição incomum dos átomos de superficie em relação os átomos do interior do sólido, onde o número de coordenação é inferior ao número de coordenação dos átomos internos.

Segundo a Empresa Brasileira de Pesquisa Agropecuária (EMBRAPA), o Brasil segue ainda como sendo o maior produtor de café no mundo, sendo a produção estimada de 49,64 milhões de sacas de café de $60 \mathrm{~kg}$ no ano de 2016, batendo mais um recorde de produção. A 


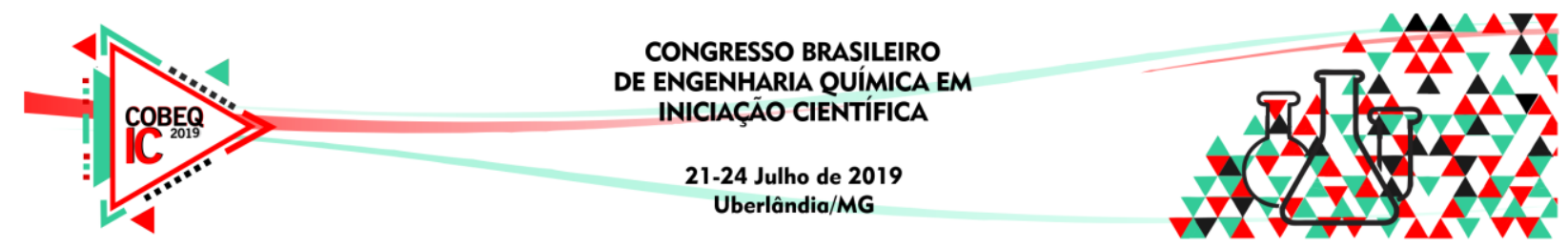

grande produção dos grãos leva consequentemente a geração de resíduos, como a casca do café que não é consumida.

No presente trabalho buscou-se avaliar a eficiência de remoção de Cádmio e Cromo, tendo em vista o baixo custo e abundância, características importantes para a utilização em processos de escala industriais.

\section{MATERIAL E MÉTODOS}

Para a realização das análises, elaborou-se um efluente sintético contendo concentrações conhecidas de Cádmio e Cromo. A fabricação de efluentes com concentrações conhecidas dos analitos visa uma caracterização precisa das amostras e da remoção dos metais pelo método escolhido, além da generalização da aplicação do método em diversas indústrias. Todos os procedimentos foram realizados nos laboratórios do Centro Universitário de Patos de Minas (UNIPAM).

\subsection{Produção e Armazenamento do Efluente Sintético}

Para a simulação do efluente, foi preparado uma mistura contendo Cádmio e Cromo, utilizando-se cloreto de Cádmio $\left(\mathrm{CdCl}_{2}\right)$ e nitrato de Cromo $\left(\mathrm{Cr}\left(\mathrm{NO}_{3}\right)_{3}\right)$ na concentração de $1 \mathrm{~mol} / \mathrm{L}$ para cada reagente. Após feita a mistura das soluções, o efluente sintético foi armazenado em frascos devidamente esterilizados e adequadamente acondicionados para não terem contato com a luz ou umidade.

\subsection{Coleta e Preparo da Casca de Café}

A casca de café empregada nessa pesquisa foi coletada na cidade de São Gotardo Minas Gerais $\left(19^{\circ} 25^{\prime} 31.1^{\prime \prime S} 46^{\circ} 15^{\prime} 38.8^{\prime \prime} \mathrm{W}\right)$. A mesma foi recolhida e armazenada em sacos de papel pardo e levada para o laboratório para armazenamento adequado. Em seguida a casca foi seca e triturada em um moinho de facas e submetida a uma peneiração, usando peneiras de 4, 9 e 28 mesh. A matéria que ficou retida na peneira de 28 mesh foi armazenada em pote de plástico (de cor escura) para evitar contato com umidade e luz.

\subsection{Tratamento do fluente Sintético Por Processo Batelada}

Para o tratamento com a casca, foram utilizadas três massas diferentes do material: 2,5; 5,0 e $10 \mathrm{~g}$ do material triturado para cada $100 \mathrm{~mL}$ de efluente e 2 tempos de contato: $2 \mathrm{e} 4 \mathrm{~h}$ para cada amostra. A mistura foi então agitada a $50 \mathrm{rpm}$ em uma mesa de agitação orbital Vortex Mixer (modelo K45-2810). Logo após a decantação, realizou-se uma filtração simples para a retirada da matéria orgânica que restou no efluente. Retirou-se uma alíquota de cada um dos filtrados para a análise de metais pesados no Espectrofotômetro de Absorção Atômica PERKIN ELMER (modelo 3300).

\section{RESULTADOS E DISCUSSÃO}




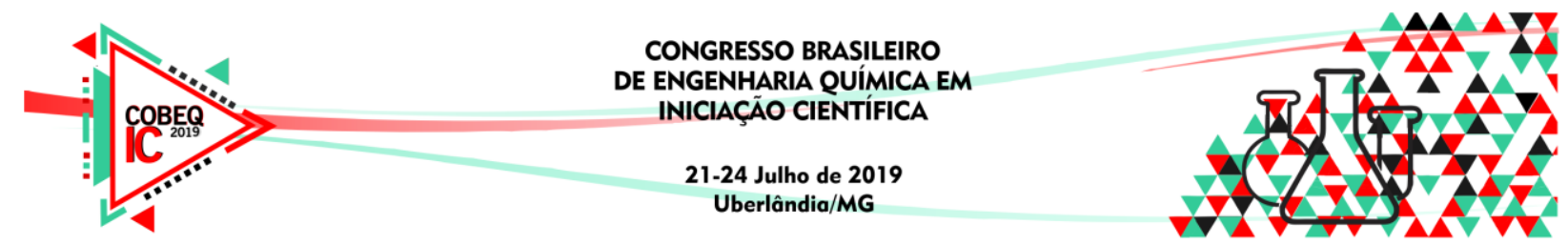

Com os resultados obtidos da leitura da concentração de Cádmio e Cromo, foram calculadas as remoções percentuais para cada condição de processo e para cada metal em análise, com mostrados na tabela 1.

Tabela 1 - Porcentagem de remoção de Cádmio e Cromo.

\begin{tabular}{|c|c|c|c|}
\hline $\begin{array}{c}\text { Massa de } \\
\text { casca de café } \\
{[\mathrm{g} / \mathrm{L}]}\end{array}$ & $\begin{array}{c}\text { Tempo de } \\
\text { contato }[\mathrm{h}]\end{array}$ & $\begin{array}{c}\text { Remoção de } \\
\text { Cádmio [\%] }\end{array}$ & $\begin{array}{c}\text { Remoção de } \\
\text { Cromo [\%] }\end{array}$ \\
\hline \hline 2,5 & 2 & 17,03 & 34,82 \\
\hline 5,0 & 2 & 17,95 & 35,40 \\
\hline 10,0 & 2 & 15,54 & 33,58 \\
\hline 2,5 & 4 & 24,19 & 38,95 \\
\hline 5,0 & 4 & 19,38 & 35,92 \\
\hline 10,0 & 4 & 22,05 & 37,70 \\
\hline
\end{tabular}

Analisando-se a Tabela 1, nota-se que houve remoção em todos os experimentos realizados, mas as maiores porcentagens de remoção foram de Cromo. Comparando se os tempos de contato, observou-se maiores valores de remoção no tempo de $4 \mathrm{~h}$, o que era esperado devido ao maior tempo de contato de adsorvente e adsorvato influenciar no processo de difusão do efluente no adsorvente. Em relação as massas de casca de café, esperava-se uma maior remoção em maiores valores de massas adicionados no processo. Entretanto, foi notado um comportamento atípico para o tratamento, pois obteve-se maiores remoções para menores massas de casca tanto para Cádmio quanto para Cromo. Resultados semelhante foram encontrados por Santos (2013), onde menores massas de casca foram mais eficientes na remoção de corantes de efluente têxtil.

\section{CONCLUSÕES}

Pôde-se concluir que a casca de café se mostrou eficiente na remoção de Cádmio e Cromo do efluente sintético, sendo que foram encontradas maiores porcentagens de remoção para Cromo.

Ao se utilizar maiores tempos de contato do adsorvente/adsorvato, acarretou em melhores porcentagens de remoção, utilizando menores massas de adsorvente, apresentou uma maior porcentagem de remoção dos metais, o que acarreta em diminuição de gastos em um processo de adsorção e a possibilidade de aplicação do método em escala industrial.

Por ser um adsorvente natural pode-se estudar o reaproveitamento da casca de café retida no papel filtro no próprio sistema de adsorção e até mesmo para outros fins, realizando os devidos tratamentos.

\section{REFERÊNCIAS}




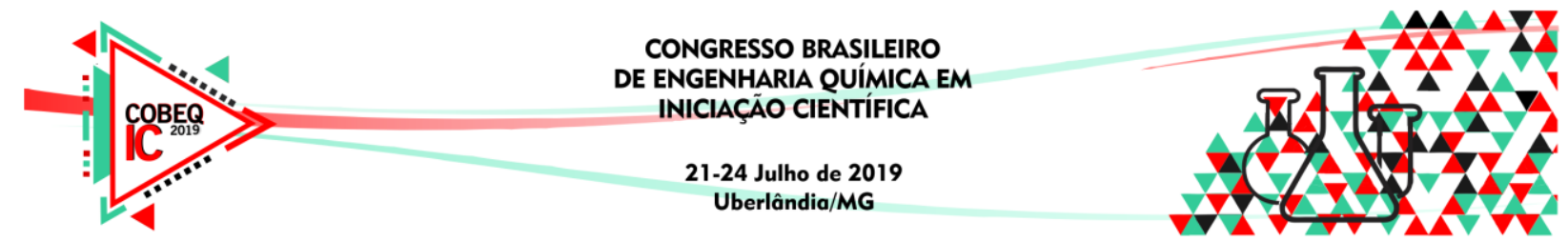

AMORIM, W. B. Estudo do Processo de Dessorção de Cromo Hexavalente Presente em Algas Marinhas Provenientes do Processo de Biossorção. FEQ , CAMPINAS, UNICAMP, Dissertação de Mestrado, 2000.

CIOLA, R. Fundamentos de catálise. 1 ed. Editora da USP, São Paulo. 1981.

EMBRAPA - Empresa Brasileira de Pesquisa Agropecuária, Ministério da Agricultura, Pecuária e Abastecimento. Disponível em: < https://www.embrapa.br/busca-denoticias/-/noticia/17220176/cafes-do-brasil-batem-recorde-de-produtividade-em-2016>. Acesso em 06 de setembro de 2017.

ONUBR, Nações Unidas no Brasil. Disponível em: < https://nacoesunidas.org/acao/agua/>. Acesso em 06 de setembro de 2017.

SANTOS, D. F. Tratamento de efluente têxtil utilizando a técnica de adsorção em casca de café. 2013. 44 f. TCC (Graduação) - Curso de Tecnologia em Processos Químicos, Universidade Federal do Paraná, Apucarana, 2013.

WALESKA E. O.; ADRIANA S. F.; LEANDRO S. O.; SONIA D. R. Untreated coffee husks as biosorbents for the removal of heavy metals from aqueous solutions. Journal of hazardous materials. 152 (2008) 1073-1081. 